This item was submitted to Loughborough's Research Repository by the author.

Items in Figshare are protected by copyright, with all rights reserved, unless otherwise indicated.

\title{
Optimum design of a watershed-based tank system for the semiarid and subhumid tropics
}

PLEASE CITE THE PUBLISHED VERSION

http://ascelibrary.org/iro/resource/1/jidedh/v137/i10/p651_s1?isAuthorized=no

PUBLISHER

(C) American Society of Civil Engineers

VERSION

AM (Accepted Manuscript)

LICENCE

CC BY-NC-ND 4.0

REPOSITORY RECORD

Smout, lan K., Mukund G. Shinde, and S.D. Gorantiwar. 2019. "Optimum Design of a Watershed-based Tank System for the Semiarid and Subhumid Tropics". figshare. https://hdl.handle.net/2134/9075. 
This item was submitted to Loughborough's Institutional Repository (https://dspace.lboro.ac.uk/) by the author and is made available under the following Creative Commons Licence conditions.

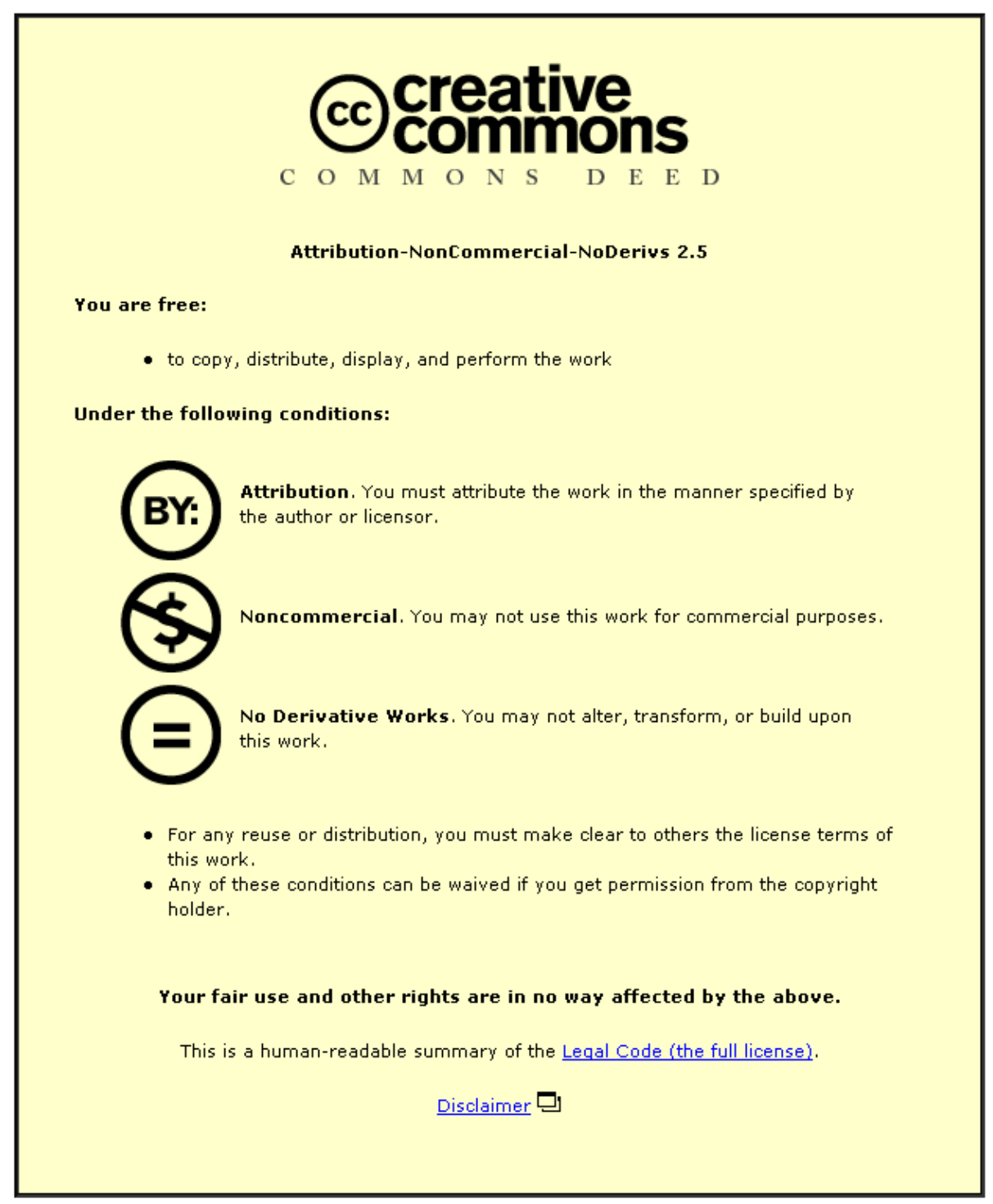

For the full text of this licence, please go to: http://creativecommons.org/licenses/by-nc-nd/2.5/ 


\title{
OPTIMUM DESIGN OF A WATERSHED BASED TANK SYSTEM FOR THE SEMIARID AND SUBHUMID TROPICS
}

\begin{abstract}
I.K.Smout $^{1}$ M.G.Shinde ${ }^{2}$, and S.D.Gorantiwar ${ }^{3}$

\section{ABSTRACT}

Small reservoirs known as tanks are constructed in watersheds of arid, semiarid and subhumid regions of India to provide supplementary or protective irrigation to crops during dry spells of the monsoon season or full irrigation during the post monsoon season. The stored water in tanks or recharged groundwater is used for this irrigation. Several models have previously been developed to design individual tanks in terms of capacity. However for optimum utilization of water generated in a watershed to meet the demands for irrigation and for downstream release, it is necessary to design the tanks together in terms of their number, locations and capacities. A comprehensive methodology for this is presented using 'stream points' i.e. possible tank locations on the main stream(s) in the watershed. Tank strategies (combination of the number of tanks, their locations at stream points and the tank type) are then generated for the identified stream points. Subsequently fields in the watershed are assigned to the catchment and the command of different tanks of a specified tank strategy. Simulation of field, tank and groundwater balance is then carried out on a daily basis, from which optimum tank dimensions are obtained for a specified tank strategy. The optimum tank strategy and corresponding optimum tank dimensions are obtained by investigating all the possible tank strategies.
\end{abstract}

\footnotetext{
${ }^{1}$ Water, Engineering and Development Centre, Loughborough University, Loughborough, UK, LE11 $3 \mathrm{TU},{ }^{2}$ Assistant Professor of Soil and Water Conservation Engineering and ${ }^{3}$ Associate Professor of Irrigation and Drainage Engineering, MPKV, Rahuri, India 413722
} 
KEY WORDS: Tanks; reservoir; watershed; semiarid; sub-humid; tropics; simulation; optimization; model

\section{INTRODUCTION}

In semi arid and sub-humid regions of India tanks (small reservoirs) are constructed to store direct rainfall and runoff from their catchment areas. The stored water and/or water recharged to aquifers due to storage of water in tanks is used for supplementary or protective irrigation during dry spells of the monsoon season and for full irrigation during the post monsoon season. In India, these tanks are constructed as part of a watershed development program. Tanks range in storage volume from a few hundred to a few thousand cubic meters. The distance between tanks varies from a few hundred to a few thousand meters. Though these tanks are constructed as part of a watershed development program, the number of tanks, their capacities and spacing are driven by rules of thumb and targets assigned to the developmental agencies. Employment generation through manual earth moving works is often a social purpose behind construction of these tanks. The hydrology of the watershed, the demand for water and the water balance among supply and demand parameters are not considered while deciding the capacity of tanks and their number. Therefore in spite of constructing thousands of tanks, relatively little irrigation potential has been created.

In each watershed there can be one or a series of tanks of varying sizes depending on the rainfall, watershed characteristics and cropping pattern in the watershed.

Therefore a whole spectrum of factors affecting the supply and demand of water in the watershed needs to be considered while deciding the capacity, number and 
locations of tanks. This includes the runoff producing characteristics of the catchment, tank characteristics, command area characteristics including land use, micro-level activities and water resources. In addition, to protect riparian rights and the environment and to consider equitable distribution of water, it is important to release a proportion of the water to flow downstream of the tanks. The existing literature (Palmer et al, 1982; Helweg and Sharma, 1983; Varma and Sharma, 1990; Srivastava, 1996, and Panigrahi and Panda, 2003) is concerned with the design of individual tank size and shape for storing and utilizing the maximum harvested water.

An integrated approach for the design of tanks in a watershed has been developed to consider all the aspects that influence supply and demand of water in the watershed. This approach designs the 'optimal system of tanks' that makes maximum volume of water available for utilization in a watershed and a specified proportion of water available for downstream water requirement, instead of designing an 'individual tank'. The paper presents the methodology devised for this approach and a simulation model - Simulation Optimization For TANKs (SOFTANK) - based on the developed methodology.

\section{WATERSHED BASED TANK SYSTEM}

The watershed based tank system consists of a series of tanks of different sizes, types (defined later) and shapes to capture, store and recharge water, to release a specified proportion of water downstream of a system and to utilize stored and recharged water for irrigation. The optimization of a watershed based tank system 
proposed in this paper is based on the concepts of integrated water storage system (IWSS) in a watershed, downstream release as explained in this section and 'tank strategy' as explained in the next section.

Water is stored for the utilization of crop production in three storage elements viz. soil, surface tanks and aquifer. These storage elements are interdependent in terms of storage/recharge and utilization, and are considered in this study as an integrated water storage system. This IWSS concept is shown schematically in Fig. 1 and described below.

Figure 1: The integrated water storage system concept (IWSS)

1. Soil: In situ rainwater harvesting (RWH) practices like trenches to harvest rainfall are also constructed in a watershed along with tanks. These in situ practices harvest a considerable volume of water, and thus reduce the flow to the tanks and increase soil water storage and groundwater recharge (Chittaranjan et al., 1997 and MPKV, 2002). These RWH practices reduce the capacity requirements of the tanks. This aspect has been considered in the methodology for designing tanks.

2. Surface tanks: Surface tanks store the runoff water for irrigation and recharge to groundwater. Water release from tanks for irrigation and seepage to groundwater create space in the reservoir to accommodate more runoff water. Reduced water levels in the tanks reduce the recharge volumes and the potential for irrigation. Irrigation to the fields increases soil moisture which ultimately enhances the runoff potential from these soils. When water is available in the tanks, less groundwater is utilized for irrigation demands. 
3. Aquifer: Water stored in the tanks recharges the aquifers. The water levels in the tanks change due to irrigation, evaporation and inflow. These changes in the water levels in the tanks affect the recharge volume. The storage capacity of the underlying aquifer controls the recharge volume. Water from the aquifer is utilized for irrigation in the watershed which reduces the release of water for irrigation from the tanks and thus makes more water available for recharge. Irrigation practices also influence the aquifer storage. For example excess irrigation to fields results in deep percolation losses that eventually reach the groundwater.

Thus these three storage elements are interlinked and changes in one storage element affect the water balance of the other two storage elements.

\section{Upstream-downstream conflict}

At present tanks are designed to harvest almost all possible rainfall and runoff in the watershed and hence the downstream release of water is not considered. This gives rise to conflicts between upstream and downstream users of water (Sakthivadivel and Scott, 2005 and Sikka and Paul, 2005). Depending on the local structures and riparian rights of water, the IWSS should receive a specified amount of water from upstream and release a specified amount downstream and the surface tank system needs to be designed accordingly. Upstream receipt and downstream release (DSR) criteria are proposed in the developed methodology. These criteria facilitate design of the tank system for a specified proportion of downstream release.

\section{Tank type}

Water from the tank may be used for irrigation to an area downstream of the tank or may be lifted for irrigation to the upstream catchment area or may be a combination 
of both these cases. In the proposed methodology the tanks have been distinguished based on the utilization pattern of water as stated above by introducing the concept of 'tank type'. Based on the location of its command area, a tank could be any of the following types.

Tank type 1: These are tanks with the command area downstream of the tank. In this case the command area is normally less than the catchment area and the catchment command ratio (CCR) is thus usually greater than one.

Tank type 2: These are tanks with the command area upstream of the tank (it should be noted that this is also the catchment area of the tank). In this case, part or all of the catchment will serve as the command area and hence the CCR is greater than or equal to one.

Tank type 3: These are the tanks with command area both upstream and downstream of the tank. In this case the downstream command and upstream catchment both serve as command area and hence the CCR is less than one.

\section{METHODOLOGY OF TANK SYSTEM DESIGN}

The developed methodology for optimum design of a tank system consists of following four steps.

- Field assignment to stream points

- Generation of tank strategies

- Catchment and command field assignment to tanks

- Water balance (tank, field and aquifer) 
The methodology of tank system design starts from the identification of 'stream points' i.e. possible tank locations on the main stream(s) in the watershed. Stream points are identified by visually inspecting the drainage line and interacting with the stake holders. These points are selected on the basis that they provide good storage for less excavation and consider the interests of the stake holders in the watershed. The approach is to select as many stream points as possible and carry out the simulation. The stream points that are optimum on the basis of cost-benefits, utilization of water for irrigation and downstream release will only be selected in the process of optimization. Different fields in the watershed are assigned to these stream points. Tank strategies (described below) are then generated for the identified stream points. Fields are then assigned to the catchment and command areas of the tanks of a tank strategy. Simulation of field, tank and groundwater balance is then carried out on a daily basis for all the tank strategies, from which the optimum tank system is designed. It is thus a four step methodology as described below and shown in Fig 2.

\section{Figure 2: Conceptual flowchart of the methodology for finding optimum tank strategy}

\section{Field assignment to stream points}

In semi arid and sub-humid regions of India, individual fields are normally less than 2 ha in area. A field outlet is considered as the point having minimum elevation on the field boundary for that field. After stream points are defined, fields in the watershed are assigned to the catchment of the nearest stream point such that the 
elevation of the stream point is lower than the elevation of the field outlet (Zcoordinate).

\section{Generation of tank strategies}

In this methodology the concept of 'tank strategy' is proposed. The tank strategy defines the number of tanks, their locations on the stream and their types. A watershed may have any number of stream points and thus tanks. For example a typical watershed of say 1000 ha may have between one and five tanks. Next an important decision needs to be made: how many tanks and where to locate those on the stream? For example if the water balance of the watershed shows the need for one tank, where would this tank be located for optimum utilization of water resources? It can take any location starting from stream point No 1 to No 5. Further as described earlier a tank may be of any 'tank type' depending on the orientation of command area around the tank. However the tank at the outlet of the watershed will be of tank type 2 only since there is no command on the downstream of the tank. The 'number of tanks', 'tank locations' and 'tank types' are interrelated and need to be integrated while planning the tank system for the watershed. Hence a combination of 'number of tanks', 'tank locations' and 'tank types' constitutes a tank strategy in this study. The number of tank strategies is a function of the number of stream points. For example there is only one tank strategy when there is only one stream point at the outlet of the watershed. The number of tank strategies increases exponentially as the number of stream points increases. There are seven tank strategies for two stream points, 31 for three, 127 for four, 511 for five and 2047 tank strategies for six stream points. These tank strategies are identified by 'tank 
strategy number' and a particular 'tank strategy number' defines one specific combination of 'number of tanks', 'tank locations' and 'tank types'.

\section{Catchment and command field assignment to tanks}

A watershed comprises different fields. These fields are 'catchment fields' or 'command fields' of a particular tank or alternatively a field is a command field to one tank and a catchment field to another tank. Catchment fields receive inflows in the form of rain and runoff whereas command fields receive inflows in the form of irrigation in addition to rain and runoff. Runoff here represents the surface runoff from upstream catchment fields and the catchments fields for a particular downstream field are assigned based on the relative elevations of the fields. The catchment fields and command fields of a particular tank change as the tank strategy changes. For example if a particular field is a catchment field of a tank at stream point No 2, the same field may be in the catchment of a tank at stream point No 1 in another tank strategy since there may not be a tank at the stream point No. 2 in that strategy. Further a 'catchment field' may become the 'command field' of a tank as the tank type (or the tank strategy) changes. If a particular stream point does not have a tank, the fields assigned to this stream point are reassigned as catchment fields to the downstream stream point where a tank is located. These fields are also assigned as command fields of the upstream stream point where a tank is located. Thus the field assignment to catchment or command area of a tank is a dynamic procedure and changes with tank strategy. Hence a procedure has been developed that assigns a particular field to a tank's catchment and (or) command depending on the relative elevation of the outlet of the field and tank. 


\section{Water Balance}

The output of a particular tank strategy is obtained in terms of the net benefits for a specified proportion of downstream release within the available water resources in the watershed. The net benefits are obtained by simulating three important water balances i.e. field water balance, tank water balance and groundwater balance. If trenches are present in the catchments of the tank, trench water balance is also simulated.

\section{Criterion for selection of a tank strategy}

A tank strategy and design that provide maximum net benefits and satisfy the specified DSR are selected as narrated below.

A downstream release (DSR) is defined in this research as the annual volume of water that passes the watershed outlet as per cent of annual volume of runoff generated in the watershed. For example, a DSR of 30\% means tanks will harvest $70 \%$ of the runoff generated in the watershed and the remaining $30 \%$ will be released downstream out of the watershed. The tank system is designed for this pre specified DSR. Field, tank and groundwater balances are simulated simultaneously on a daily basis for this purpose. Initial tank capacities are determined with the design runoff depth (DRD). Design runoff depth is an empirical value of minimum runoff depth for the entire watershed that is assumed at the beginning of the simulation to facilitate the computation of tank capacity. DRD multiplied by the catchment area of the tank gives the volume of runoff for which tank dimensions are optimized. At the end of the simulation, the output DSR is obtained. The output DSR is the function of tank size, water use and climate. Hence the output DSR may 
or may not match the input DSR. Therefore the difference between the DSRs is checked for an acceptable range i.e. output DSR $=$ input DSR \pm allowable deviation (e.g. $30 \% \pm 10 \%$ ). If the output DSR is not within the allowable limit, the tank capacity is increased (or decreased) and the simulation is repeated again. The procedure is repeated till the DSR criterion is met. When the DSR criterion is met, net benefits for the tank strategy are estimated. In this way the net benefits for all tank strategies are calculated. The tank strategy with capacities of the tanks that produces maximum net benefits is chosen as the optimum tank system for the watershed. The conceptual flowchart of the methodology is shown in Fig 2.

\section{Tank water balance}

There is daily (or intermittent) inflow to and outflow from the tank. It is therefore necessary to simulate these inflow and outflow processes on a daily basis to determine the storage capacity of the tank by a water balance approach. Simulation of the tank water balance should include all inflows to and outflows from the tank. The inflows are the direct rainfall over the tank surface; surface runoff from the fields in the catchment of the tank and overflows from the upstream tanks, if any. The outflows are evaporation, seepage, excess overflows and irrigation given to crops from the tank. Continuity equation (Eq. 1) was developed to simulate the water balance over tank system in the watershed.

$S_{i}^{j}=S_{i-1}^{j}+P_{i} A_{\text {surf }}^{j}+R_{i}^{j} A_{\text {cat }}^{j}+\sum_{i=1}^{L_{j}} O_{i}^{j, k}-\sum_{m=1}^{M_{j}} \sum_{k=1}^{K} W D_{i, m, k}^{j} A I_{i, m, k}^{j}-D P t_{i}^{j}-E_{i}^{j} A_{i}^{j}-O_{i}^{j}$

$W D_{t, m, k}^{f}=\frac{l s_{t m k}^{f}}{\eta_{\sigma_{m}}^{f} \eta_{\alpha_{m}}^{f}}$ 
Where,

$$
\begin{aligned}
& S_{i}^{j} \quad=\text { Tank storage of } j^{\text {th }} \text { tank on } i^{\text {th }} \text { day, } \mathrm{m}^{3} \\
& S_{i-1}^{j} \quad=\text { Tank storage of } j^{\text {th }} \text { tank on }(i-1)^{\text {th }} \text { day, } \mathrm{m}^{3} \\
& P_{i} \quad=\text { Rain on } i^{\text {th }} \text { day, } \mathrm{m} \\
& A_{\text {surf }}^{j} \quad=\text { Tank top surface area of } j^{\text {th }} \text { tank, } \mathrm{m}^{2} \\
& R_{i}^{j} \quad=\text { Runoff to the } j^{\text {th }} \text { tank on } i^{\text {th }} \text { day, } \mathrm{m} \\
& A_{\text {cat }}^{j} \quad=\text { Catchment area of } j^{\text {th }} \text { tank, } \mathrm{m}^{2} \\
& O_{i}^{j, k}=\text { Overflow from } k^{\text {th }} \text { tank, an overflow contributing tank of } j^{\text {th }} \text { tank } \\
& \text { on } i^{\text {th }} \text { day, } \mathrm{m}^{3} \\
& D P t_{i}^{j} \quad=\text { Seepage from } j^{\text {th }} \text { tank on } i^{\text {th }} \text { day, } \mathrm{m}^{3} \\
& E_{i}^{j} \quad=\text { Evaporation from } j^{\text {th }} \text { tank on } i^{\text {th }} \text { day, } \mathrm{m} \\
& A_{i}^{j} \quad=\text { Water surface area of } j^{\text {th }} \text { tank on } i^{\text {th }} \text { day, } \mathrm{m}^{2} \\
& O_{i}^{j} \quad=\text { Overflow from } j^{\text {th }} \text { tank on } i^{\text {th }} \text { day, } \mathrm{m}^{3} \\
& l s_{t m, k}^{l} \quad=\text { Irrigation depth to be applied for irrigating } k^{\text {th }} \text { crop grown on } \\
& m^{\text {th }} \text { field allocated to } j^{\text {th }} \text { tank from water from } j^{\text {th }} \text { tank on } \\
& i^{\text {th }} \text { day, m } \\
& L_{j} \quad=\text { Total number of overflow contributing tanks to } j^{\text {th }} \text { tank } \\
& M_{j} \quad=\text { Total number of fields allocated to } j^{\text {th }} \text { tank } \\
& \mathrm{K}=\text { Total number of crops to be irrigated } \\
& W D_{t, m, k}^{l} \quad=\text { Water to be delivered from } j^{\text {th }} \text { tank for irrigating } k^{\text {th }} \text { crop on } m^{\text {th }}
\end{aligned}
$$


field allocated to $j^{\text {th }}$ tank on $i^{\text {th }}$ day, $\mathrm{m}$

$A I_{i m k}^{\xi} \quad=$ Area to be irrigated of $k^{\text {th }}$ crop grown on $m^{\text {th }}$ field allocated to

$j^{\text {th }}$ tank from water from $j^{\text {th }}$ tank on $i^{\text {th }}$ day, $m^{2}$

$\eta_{\sigma_{\mathrm{m}}}^{z} \quad=$ Conveyance efficiency of irrigating $m^{\text {th }}$ field allocated to $j^{\text {th }}$ tank

$n_{d_{m}}^{2} \quad=$ Distribution efficiency of irrigating $m^{\text {th }}$ field allocated to $j^{\text {th }}$ tank

The initial tank capacity required for performing the tank water balance is computed by multiplying the catchment area of a tank by the empirically considered design runoff depth (DRD). Simulation starts from 1st June of each year (before the rainy season) and the storage in the tank at the start of the simulation is considered zero.

Inflow: The inflows to the tank are direct rainfall over the surface area of the tank, runoff as computed by SCS-CN method (Sharpley and Williams, 1990) from all fields in the catchment of the tank and the overflow from the upstream tank.

Evaporation. Water is lost continuously due to evaporation from the water surface area in the tank. The depth of evaporation is estimated by the Penman method (1948). Evaporation volume is the product of the evaporation depth and the water surface area of the tank on that day. The tank water surface area depends on inflow into and outflow from the tank and is calculated daily to estimate the evaporation loss using the stage-area and storage volume relationships of the tank.

Seepage: Water is lost due to seepage from the bottom and the sides of the tank. The volume of water lost due to seepage is obtained by multiplying the seepage rate by the wetted area of the tank. The seepage rate is user defined. Its value can be estimated from standard textbooks or field measurements. The wetted area of the 
tank is updated daily from stage-area and storage volume relationships. It is assumed that there is no upward flow from the groundwater to the tanks as groundwater is more than $2 \mathrm{~m}$ below the tank bottom.

Irrigation: Irrigation to different crops on different fields in the command area of the tank is provided according to specified irrigation scheduling criteria. In addition, the irrigation water diverted from the tank (or groundwater storage) depends on crop, soil and climatic parameters. If on the day of irrigation, sufficient water is available in the tank, irrigation is given to all fields. If the water availability in the tank is less, priority for irrigation is given to the fields close to the tanks, so that the losses in irrigation and cost of conveyance are minimized. The water levels in the tank are updated after release of water for irrigation.

Overflow from the tanks occurs when inflow exceeds the maximum capacity of the tank. It should be noted that the outflow parameters, 'seepage' and 'irrigation' of the tank water balance are inflow parameters of groundwater balance and field water balance, respectively.

Tank dimensions: The dimensions of the tank are optimized with Lagrange multiplier method for the selected tank geometry (rectangular or square prism, inverted truncated pyramid, cylindrical or hemispherical). This method consists of the function of variables, which is to be minimized (Eq 2 ) subject to the set of constraints (Eq. 3).

Minimize $f(\mathrm{X})$

$\mathrm{X}=x_{i}, \quad i=1, n$

Subject to 
$g_{j}(\mathrm{X})=0, \quad j=1,2, \ldots . ., m$

The Lagrange function, $\mathrm{L}$, is defined by introducing one Lagrange multiplier $\lambda_{\mathrm{j}}$ for each constraint $\mathrm{g}_{\mathbf{j}}(\mathbf{X})$ as (Eq 4)

$L\left(x_{1}, x_{2}, \ldots \ldots ., x_{n}, \lambda_{1}, \lambda_{2}, \ldots \ldots ., \lambda_{m}\right)=f(\mathrm{X})+\lambda_{1} g_{1}(\mathrm{X})+\lambda_{2} g_{2}(\mathrm{X})+\ldots . .+\lambda_{m} g_{m}(\mathrm{X})$

By treating $L$ as a function of the $n+m$ unknowns, $x_{1}, x_{2}, \ldots \ldots \ldots, x_{n}, \lambda_{1}, \lambda_{2}, \ldots \ldots, \lambda_{m}$, the necessary conditions for the extreme of L, which also corresponds to the solution of the original problem stated in equations (2) and (3) are given by equations (5) and (6).

$\frac{\partial L}{\partial x_{i}}=\frac{\partial f}{\partial x_{i}}+\sum_{j=1}^{m} \lambda_{j} \frac{\partial g_{j}}{\partial x_{i}}=0, \quad i=1,2, \ldots \ldots ., n$

$\frac{\partial L}{\partial \lambda_{j}}=g_{j}(\mathrm{X})=0, \quad j=1,2, \ldots \ldots, m$

Equations (5) and (6) represent $(n+m)$ equations in terms of $(n+m)$ unknowns, $x_{\mathrm{i}}$ and $\lambda_{\mathrm{j}}$. In the present study, the function to be minimized is seepage and evaporation area of the tank such that the required quantity of water is stored in the tank. The details of the optimization of tank dimensions with Lagrange multiplier method for the four tank geometries - rectangular prism, inverted truncated pyramid, cylindrical and hemispherical are presented by Shinde (2006).

After applying the tank water balance for one year i.e. up to 30 May, if the computed system overflow (this is the overflow from the last tank that goes out of the watershed) is not within the desired range of targeted overflows (DSR), the tank 
sizes are increased (or decreased) and simulation is carried out for the revised tank capacity. The procedure is repeated till the overflow criterion (DSR) is satisfied.

It is assumed that the base flow from tank catchments has no impact on tank water balance since all tanks have shallow depths.

\section{Field water balance}

The field water balance is based on the principle of mass conservation applied to the soil water reservoir. By this principle the difference between the amounts of water going into and withdrawn from the soil water reservoir during a certain period is equal to the change in water storage of the reservoir during the same period. The component processes of the soil water balance are rainfall, runoff, infiltration, redistribution, drainage, evaporation, transpiration and upward flow of water from the water table by capillary rise. The contribution to soil water storage from capillary rise is considered as negligible. For the purpose of water balance the soil reservoir is divided into 3 zones (or layers): root zone, soil zone and vadose zone (Fig. 3). The soil in the vadose zone is assumed to be at field capacity. Moisture extraction by plant roots, evaporation and percolation occurs from the root zone whereas only percolation occurs from the soil zone. The depths of the root zone and soil zone of a soil reservoir vary with crop growth and are influenced by the effective root depth that varies with time and from which the crop extracts water.

\section{Figure 3: Conceptual field water balance model}

The water balance in the root zone is governed by rainfall, runoff, irrigation, actual evapotranspiration and percolation to the lower soil zone. The water balance in the 
soil zone is governed by percolation from the root zone and deep percolation out of this zone to the vadose zone. The vadose zone is only considered in terms of the water percolating from soil zone which contributes to the ground water and causes groundwater table fluctuations in the vadose zone.

The water balance in the root zone is performed on a daily basis by equation (7).

$$
\theta_{i}^{R} * Z_{i}=\theta_{i-1}^{R} Z_{i-1}+P_{i}+I_{S_{i}}+I_{G_{i}}+\theta_{i-1}^{S} * \Delta Z_{i}-S R_{i}-D \operatorname{Pr}_{i}-E T_{a_{i}}
$$

Where,

$$
\begin{aligned}
& \theta_{i}^{R} \quad=\text { Soil moisture content of root zone on } i^{\text {th }} \text { day, } \mathrm{m} / \mathrm{m} \\
& Z_{i} \quad=\text { Root zone depth on } i^{\text {th }} \text { day, } \mathrm{m} \\
& P_{i} \quad=\text { Rainfall on } i^{\text {th }} \text { day, } \mathrm{mm} \\
& I_{S_{i}} \quad=\text { Irrigation on } i^{\text {th }} \text { day from tank, } \mathrm{m} \\
& I_{G_{i}} \quad=\text { Irrigation on } i^{\text {th }} \text { day from groundwater, } \mathrm{m} \\
& \Delta Z_{i} \quad=\text { Incremental root zone depth on } i^{\text {th }} \text { day, } \mathrm{m} \\
& \theta_{i}^{S} \quad=\text { Soil moisture content of soil zone on } i^{\text {th }} \text { day, } \mathrm{m} / \mathrm{m} \\
& S R_{i} \quad=\text { Runoff on } i^{\text {th }} \text { day, } \mathrm{m} \\
& D \mathrm{Pr}_{i} \quad=\text { Deep percolation from root zone on } i^{\text {th }} \text { day, } \mathrm{m} \\
& E T_{a} \quad=\text { Actual evapotranspiration from root zone on } i^{\text {th }} \text { day, mm } \\
& E T a_{i}=E \operatorname{ETm}_{i} \quad \text { if } \quad\left(\theta_{i}^{R}-\theta_{i}^{\mathrm{wp}}\right)>(1-p)\left(\theta_{i}^{\text {fc }}-\theta_{i}^{\mathrm{wp}}\right) \\
& E T a_{i}=\frac{\left(\theta_{i}^{R}-\theta_{i}^{w p}\right)}{(1-p)\left(\theta_{i}^{f c}-\theta_{i}^{w p}\right)} E T m_{i} \quad \text { if }\left(\theta_{i}^{R}-\theta_{i}^{w p}\right) \leq(1-p)\left(\theta_{i}^{f c}-\theta_{i}^{w p}\right)
\end{aligned}
$$


Where,

$\theta_{i}^{f c}=$ Soil moisture content of root zone at field capacity on $i^{\text {th }}$ day, mm

$\theta_{i}^{w p} \quad=$ Soil moisture content of root zone at wilting point on $i^{\text {th }}$ day, mm

$E T m_{i}=$ Crop evapotranspiration on $i^{\text {th }}$ day, mm

$K c_{i} \quad=$ Crop coefficient on $i^{\text {th }}$ day

$E T o_{i}=$ Reference crop evapotranspiration on $i^{\text {th }}$ day, mm (estimated by

Penman-Monteith method)

$p \quad=$ Soil water depletion factor

Deep percolation from the root zone to the soil zone is given by equation (11).

$\operatorname{DPr}_{i}=\operatorname{Max}\left\{\left(\theta_{i-1}^{R} Z_{i-1}+\theta_{i-1}^{S} \Delta Z_{i-1}\right)+\left(P_{i}+I_{S_{i}}-S R_{i}\right)-\theta_{f} Z_{i}-E T a_{i}, \quad 0\right\}$

Where

$\theta_{f} \quad=$ Soil moisture content at field capacity, $\mathrm{m} / \mathrm{m}$

The water content in the soil zone changes depending on the depth of water percolating from the root zone and is given by equations (12) and (13)

$\theta_{i}^{S}=\theta_{i-1}^{S} \quad$ if $D \operatorname{Pr}_{i} \leq 0$

$\theta_{i}^{S}=\min \left\{\left[\theta_{i-1}^{S}+\left(\frac{D \mathrm{Pr}_{i}}{Z_{m}-Z_{i}}\right)\right], \theta_{f}\right\}$, if $D \operatorname{Pr}_{i}>0$

Where,

$Z_{m} \quad=$ the maximum possible root zone depth, $\mathrm{m}$ 
If $\theta_{i}^{s}$ calculated by equations (12) and (13) is more than the water content at field capacity in the soil zone, there will be deep percolation out of the soil zone. Deep percolation out of the soil zone, $D P_{i}$ is given by equation (14).

$D P_{i}=\left(\theta_{f}-\theta_{i}^{S}\right)\left(Z_{m}-Z_{i}\right)$

The water percolating down from the soil zone contributes to the groundwater storage since the vadose zone is considered to be at field capacity. As the inflow parameter 'irrigation' and outflow parameter 'actual evapotranspiration' of field water balance are influenced by the type of the field, the field balance is carried out separately for agricultural, horticultural and agroforestry fields.

The inflow and outflow parameters of the field water balance are also influenced by the micro level activities such as trenching and terracing. Runoff from a trenched field is less and infiltration is more due to the storage capacity of the trench. While performing the water balance of agricultural, horticultural and agroforestry fields, the influence of these micro level activities is considered. The presence of trenches and bunds on the fields changes their hydrology. A trench water balance is applied in conjunction with the field water balance for the trenched fields (Shinde et al. 2005). Infiltration from the trenches is computed with the Green-Ampt equation. The outflow parameter ‘deep percolation' and inflow parameter 'irrigation' of the field water balance are the inflow parameter of groundwater balance and the outflow parameter of the tank water balance, respectively.

While performing the field water balance, it is assumed that the total depth of effective rainfall from different storms and any irrigation applied are lumped on a daily basis as input to the soil reservoir at the beginning of the day, and that the 
entire water infiltrates into the soil reservoir. It is also assumed that the soil reservoir responds to water application by reaching equilibrium instantaneously. The infiltrated water is redistributed uniformly over the effective crop root zone and the water remaining in excess of the corresponding soil storage capacity, percolates out of the root zone.

\section{Groundwater balance}

The geology of the Maharashtra state in India consists of a weathered zone of shallow unconfined strata underlain by hard rock made of basalt. Hence the aquifers are shallow and unconfined. Groundwater from these aquifers is used for irrigating the crops in the watershed. A simple bucket type modeling approach is adopted in this study to represent the groundwater balance, which is coupled with the field and tank water balance. Deep percolation from the soil zone (including infiltration as a result of micro level activities) from the field water balance and seepage from the tank water balance are the daily inflow parameters of the groundwater balance. The outflow parameter 'irrigation' is the inflow parameter of the field water balance. The groundwater balance is performed by the equation (15).

$$
A q B_{i} \phi=A q B_{i-1} \phi+D P_{i-1}+D P t_{i-1}-I_{g_{i-1}}-O U_{i-1} \pm G F_{i-1}
$$

Where

Aq $\quad=$ Areal extent of aquifer, $\mathrm{m}^{2}$

$B_{i} \quad=$ Average thickness of the saturated part of aquifer on $i^{\text {th }}$ day, $\mathrm{m}$

$\phi \quad=$ Specific yield of the aquifer

$D P_{i-1} \quad=$ Deep percolation on $(i-1)^{\text {th }}$ day (from field water balance), $\mathrm{m}^{3}$ 
$D P t_{i-1}=$ Seepage on $(i-1)^{\text {th }}$ day (from tank water balance), ${ }^{3}$

$I_{g-1}=$ Groundwater irrigation on $(i-1)^{t h}$ day, $\mathrm{m}^{3}$

$O U_{i-1}=$ Other use on $(i-1)^{t h}$ day, $\mathrm{m}^{3}$

$G F_{i-1}=$ Groundwater flow on $(i-1)^{\text {th }}$ day, $\mathrm{m}^{3}$

It was assumed for the groundwater balance that the aquifer boundaries coincide with the watershed boundaries. Groundwater flow is the inflow and outflow across the boundary of the aquifer. Inflow and outflow may be considered as equal in the absence of any data. Other use comprises any water used for domestic, animals and industrial purposes.

\section{Project economics}

The net benefits derived from a particular tank strategy are estimated in terms of total costs and total benefits from the strategy. Total costs consist of the fixed cost, maintenance cost, and crop cultivation cost. Fixed costs comprises the costs of tanks, wells, pumps, pipeline, trenches, horticultural plantations, irrigation system etc. All fixed costs are converted to their annualized values by using equation (16).

$$
A=P V \frac{i(1+i)^{n}}{(1+i)^{n}-1}
$$

The discount rate in the equation (16) is modified for inflation rate as below.

$$
i=\frac{(1+i m)}{(1+i f)}-1
$$

Where
A = annual value
$\mathrm{i} \quad=$ discount rate (fraction) 


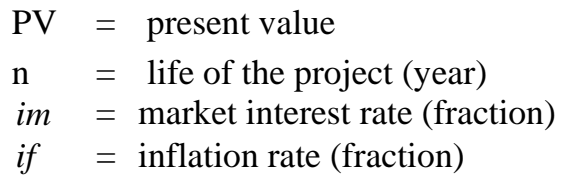
value of the main product (e.g. grain) and any by-product (e.g. straw). The annual cost is subtracted from the annual benefits to obtain the net benefits.

\section{THE MODEL}

The methodology developed and described in this study has been converted into a simulation model and coded in 'C' language and the resulting model is named as Simulation Optimization For Tanks (SOFTANK)

\section{Input to the model}

Climatic data: Daily climatic values of rainfall, temperature, relative humidity, sunshine hours and wind velocity.

Watershed data: Individual field data (dimensions, topography), stream point coordinates, soil data, crop data and existing tanks (if any) data.

Irrigation strategy: Irrigation strategy is the combination of management allowed deficit (MAD) and percentage of deficit to be met. The limits of MAD and percentage deficit to be met are input to the model. 
Tank strategy: The number of stream locations where tank construction is possible and the desired shapes for the tanks (square or rectangular prism, truncated pyramid, truncated cone, cylindrical, parabolic or spherical).

\section{Output}

The output of the model is an optimized tank strategy comprising the number of tanks, the location, type and size of each tank and the irrigation schedule for each crop cultivated on each field.

The model can be used in four different modes i.e. calibration, evaluation, simulation and optimization as described below.

\section{Calibration mode}

Existing data on the watershed and tanks are used for calibrating the model for the specific watershed. Constants of the Green-Ampt infiltration equation, CN values of the SCS-CN method of estimating runoff and specific yield of the shallow unconfined aquifer are the calibration parameters. Calibration is performed for infiltration, runoff and groundwater level. The model is run in calibration mode for different values of the calibration parameters and the actual and estimated values of infiltration, runoff and groundwater levels are compared through the root mean square error (RMSE).

\section{Evaluation mode}

SOFTANK in evaluation mode is used to evaluate an existing tank strategy for its performance assessment. In evaluation mode the existing dimensions of the tank system, irrigation and crop growing practices are considered. By running the model 
in this mode, changes in the tank system management or irrigation strategy can be suggested to improve the performance of the existing tank system in the watershed.

\section{Simulation mode}

SOFTANK model is used in simulation mode to simulate a particular tank strategy for the watershed. In this mode, tank dimensions are optimized for the specified DSR criterion. Different management options can be simulated and compared in the simulation mode.

\section{Optimization mode}

In optimization mode, the SOFTANK in simulation mode is run for several possible tank strategies. The tank strategy giving maximum net benefits with output DSR within the range of input DSR is selected as the 'optimum tank strategy' for the watershed.

\section{CONCLUSION}

A review of existing methodologies for tank design indicated the need for further development of an approach suitable for design of watershed based tank systems in semiarid and subhumid tropics. The approach followed in this paper provides a suitable methodology for optimally designing the watershed based tank systems. This is achieved by generating tank strategies based on the number of stream points in the watershed, simulating field, tank and groundwater balances for these strategies and selecting the optimum strategy based on net benefits. The three storage elements i.e. soil, tank and aquifer are integrated while deciding the optimum tank strategy. Appropriate consideration is given to the release of water for downstream users and 
ecological reasons. The mitigation effect of in situ rainwater harvesting practices on the inflow to the tanks is included while deriving the optimum tank strategy. The approach considers the optimum harvesting of water by considering the in situ structures in the watershed such as trenches and ex situ structures(i.e. tanks). The methodology has been converted into computer model SOFTANK and the model can be run in four modes-calibration, evaluation, simulation and optimization. The SOFTANK model can be used for evaluating an existing tank system, suggesting appropriate management changes in operating the existing tank systems and for deriving the optimum tank system for a watershed. 


\section{APPENDIX I REFERENCES}

Chittranjan, S., Patnaik, U. S. Adhikari, R. N., Rao R. M., Rao, M. B. Husenappa, V. and James, E. V. (1997) Soil and water conservation measures in vertisols of semi-arid region of south India. Journal of Agricultural Engineering (India), 34(1):34-42 ISSN 0256-6524.

Helweg, O.J and Sharma, P.N. (1983) Optimum design of small reservoirs (Tanks). Water Resources Research, 19(4), 881-885.

MPKV (2002) Research Review Report on Soil and Water Conservation Engineering, Mahatma Phule Krishi Vidyapeeth (MPKV) Rahuri, India.

Palmer W. L., Barfield B. J. and. Haan C. T (1982) Sizing farm reservoirs for supplemental irrigation of corn . Part I: Modelling reservoir size yield relationship. Transactions of American Society of Agricultural Engineers: 372-76.

Panigrahi, B. and Panda, S. N. (2003) Optimal sizing of on farm reservoir for supplemental irrigation. Journal of Irrigation and Drainage Engineering, 129(2): 117-128.

Penman, H. L. (1948) Natural evaporation from open water, bare soil and grass. Proceedings of Royal Society, London, A193, 120-146.

Sakthivadivel, R. and Scott, C.A. (2005) Upstream-downstream complementarities and tradeoffs: Opportunities and constraints in watershed development in water scarce regions, in Sharma, B.R. Samra, J.S., Scott, C.A. and Wani, S.P. (eds.) Watershed Management Challenges, Improving Productivity, Resources and Livelihoods New Delhi, India, 173-185. 
Sharpley A. N. and Williams J. R. eds. (1990). EPIC-Erosion productivity impact calculator: (1) Model documentation. Technical Bulletin, 1768, US Dept. of Agriculture, 235

Shinde M., Smout, I and Gorantiwar, S. (2005). Assessment of water harvesting and ground water recharge through continuous contour trenches. Proceedings of International Symposium on Management of Aquifer Recharge, Berlin 10-16 June 2005. UNESCO IHP-VI, Series on Groundwater No. 13, pp227-235

Shinde M.G. (2006) Optimization of tank irrigation systems in watersheds of semiarid and subhumid tropics. A $\mathrm{PhD}$ thesis submitted to Loughborough University, Loughborough, UK.

Sikka, A. K. and Paul, D. K. (2005) Upper catchment management: opportunities for developing linkages, proposals and partnerships, in Sharma, B.R. Samra, J.S., Scott, C.A. and Wani, S.P. (eds.) Watershed Management Challenges, Improving Productivity, Resources and Livelihoods, New Delhi, India, 283-292.

Srivastava R. C. (1996) Design of runoff recycling irrigation system for rice cultivation. Journal of Irrigation and Drainage Engineering, 122 (6): 331-335.

Varma, H.N. and Sharma, P.B.S (1990 ) Design of storage tanks for water harvesting in rainfed area, Agricultural Water Management, 18 (3), 195-208. 


\section{APPENDIX II NOTATION}

\begin{tabular}{|c|c|}
\hline A & = Annual value \\
\hline$A_{i}^{j}$ & $=$ Water surface area of $j^{\text {th }}$ tank on $i^{\text {th }}$ day, $\mathrm{m}^{2}$ \\
\hline$A_{c a t}^{j}$ & $=$ Catchment area of $j^{\text {th }}$ tank, $\mathrm{m}^{2}$ \\
\hline$A_{\text {surf }}^{j}$ & $=$ Tank top surface area of $j^{\text {th }}$ tank, $\mathrm{m}^{2}$ \\
\hline$A I_{i m,}^{i}$ & $=$ Area to be irrigated of $k^{\text {th }}$ crop grown on $m^{\text {th }}$ field allocated to \\
\hline & $j^{\text {th }}$ tank from water from $j^{\text {th }}$ tank on $i^{\text {th }}$ day, $m^{2}$ \\
\hline$A q$ & $=$ Areal extent of aquifer, $\mathrm{m}^{2}$ \\
\hline$B_{i}$ & $=$ Average thickness of the saturated part of aquifer on $\mathrm{i}^{\text {th }}$ day, $\mathrm{m}$ \\
\hline$D P_{i}^{j}$ & $=$ Deep percolation from $j^{\text {th }}$ tank on $i^{\text {th }}$ day, $\mathrm{m}^{3}$ \\
\hline$D P_{i-1}$ & $=$ Deep percolation on ( $\mathrm{i}-1)^{\mathrm{th}}$ day (from field water balance), $\mathrm{m}^{3}$ \\
\hline$D P t_{i-1}$ & $=$ Deep percolation $(\mathrm{i}-1)^{\mathrm{th}}$ on day (from tank water balance), $\mathrm{m}^{3}$ \\
\hline$D \operatorname{Pr}_{i}$ & $=$ Deep percolation from root zone on $i^{\text {th }}$ day, $\mathrm{m}$ \\
\hline$E T_{a}$ & $=$ Actual evapotranspiration from root zone on $i^{\text {th }}$ day, mm \\
\hline$E T_{i}$ & $=$ Crop evapotranspiration on $i^{\text {th }}$ day, mm \\
\hline$E T o_{i}$ & $=$ Reference crop evapotranspiration on $i^{\text {th }}$ day, mm \\
\hline$E_{i}^{j}$ & $=$ Evaporation from $j^{\text {th }}$ tank on $i^{\text {th }}$ day, $\mathrm{m}$ \\
\hline$G F_{i-1}$ & $=$ Groundwater flow on $(\mathrm{i}-1)^{\text {th }}$ day, $\mathrm{m}^{3}$ \\
\hline & $=$ Discount rate (fraction) \\
\hline
\end{tabular}




$$
\begin{aligned}
& \text { im } \quad=\text { market interest rate (fraction) } \\
& \text { if } \quad=\text { inflation rate (fraction) } \\
& I_{g-1} \quad=\text { Groundwater irrigation on }(\mathrm{i}-1)^{\text {th }} \text { day, } \mathrm{m}^{3} \\
& I_{G_{i}} \quad=\text { Irrigation on } i^{\text {th }} \text { day from groundwater, } \mathrm{m} \\
& I_{S_{i}} \quad=\text { Irrigation on } i^{\text {th }} \text { day from tank, } \mathrm{m} \\
& I s_{\mathrm{k} m, k}^{S} \quad=\text { Irrigation depth to be applied for irrigating } k^{\text {th }} \text { crop grown on } \\
& m^{\text {th }} \text { field allocated to } j^{\text {th }} \text { tank from water from } j^{\text {th }} \text { tank on } \\
& i^{\text {th }} \text { day, } \mathrm{m} \\
& \boldsymbol{K}=\text { Total number of crops to be irrigated } \\
& K c_{i} \quad=\text { Crop coefficient on } i^{\text {th }} \text { day } \\
& L_{j} \quad=\text { Total number of overflow contributing tanks to } j^{\text {th }} \text { tank } \\
& M_{j} \quad=\text { Total number of fields allocated to } j^{\text {th }} \text { tank } \\
& \mathrm{n} \quad \quad=\text { Life of the project (year) } \\
& O_{i}^{j} \quad=\text { Overflow from } j^{\text {th }} \text { tank on } i^{\text {th }} \text { day, } \mathrm{m}^{3} \\
& O_{i}^{j, k}=\text { Overflow from } k^{\text {th }} \text { tank, an overflow contributing tank of } j^{\text {th }} \text { tank } \\
& \text { on } i^{\text {th }} \text { day, } \mathrm{m}^{3} \\
& O U_{i-1} \quad=\text { Other use on }(i-1)^{\text {th }} \text { day, } \mathrm{m}^{3} \\
& p \quad=\text { Soil water depletion factor } \\
& P_{i} \quad=\text { Rain on } i^{\text {th }} \text { day }, \mathrm{m}
\end{aligned}
$$


$R_{i}^{j} \quad=$ Runoff to the $j^{\text {th }}$ tank on $i^{\text {th }}$ day, m

$S R_{i} \quad=$ Runoff on $i^{\text {th }}$ day, $\mathrm{m}$

$S_{i}^{j} \quad=$ Tank storage of $j^{\text {th }}$ tank on $i^{\text {th }}$ day, $\mathrm{m}^{3}$

$S_{i-1}^{j} \quad=$ Tank storage of $j^{\text {th }}$ tank on $(i-1)^{\text {th }}$ day, $\mathrm{m}^{3}$

$W D_{t, m, k}^{l}=$ Water to be delivered from $j^{\text {th }}$ tank for irrigating $k^{\text {th }}$ crop on $m^{\text {th }}$ field allocated to $j^{\text {th }}$ tank on $i^{\text {th }}$ day, m

$Z_{i} \quad=$ Root zone depth on $i^{t h}$ day, $m$

$\Delta Z_{i} \quad=$ Incremental root zone depth on $i^{\text {th }}$ day, $\mathrm{m}$

$Z_{m} \quad=$ Maximum possible root zone depth, $\mathrm{m}$

$\eta_{\sigma_{m}}^{z} \quad \quad=$ Conveyance efficiency of irrigating $m^{\text {th }}$ field allocated to $j^{\text {th }}$ tank

$\eta_{\varpi_{m}}^{l} \quad=$ Distribution efficiency of irrigating $m^{\text {th }}$ field allocated to $j^{\text {th }}$ tank

$\phi \quad=$ Specific yield of the aquifer

$\theta_{f} \quad=$ Soil moisture content at field capacity, $\mathrm{m} / \mathrm{m}$

$\theta_{i}^{S} \quad=$ Soil moisture content of soil zone on $i^{\text {th }}$ day, $\mathrm{m} / \mathrm{m}$

$\theta_{i}^{R} \quad=$ Soil moisture content of root zone on $i^{\text {th }}$ day, $\mathrm{m} / \mathrm{m}$

$\theta_{i}^{f c} \quad=$ Soil moisture content of root zone at field capacity on $i^{\text {th }}$ day, mm

$\theta_{i}^{w p} \quad=$ Soil moisture content of root zone at wilting point on $i^{\text {th }}$ day, mm 


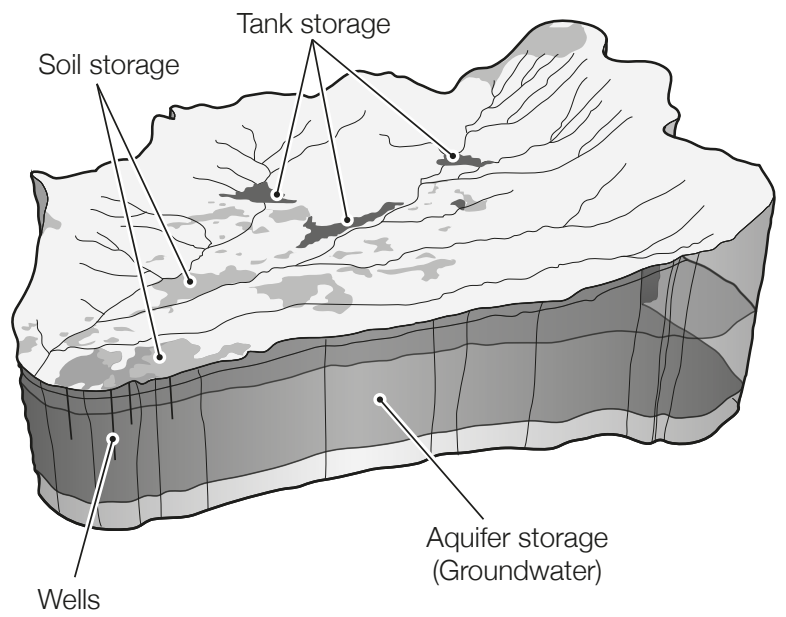




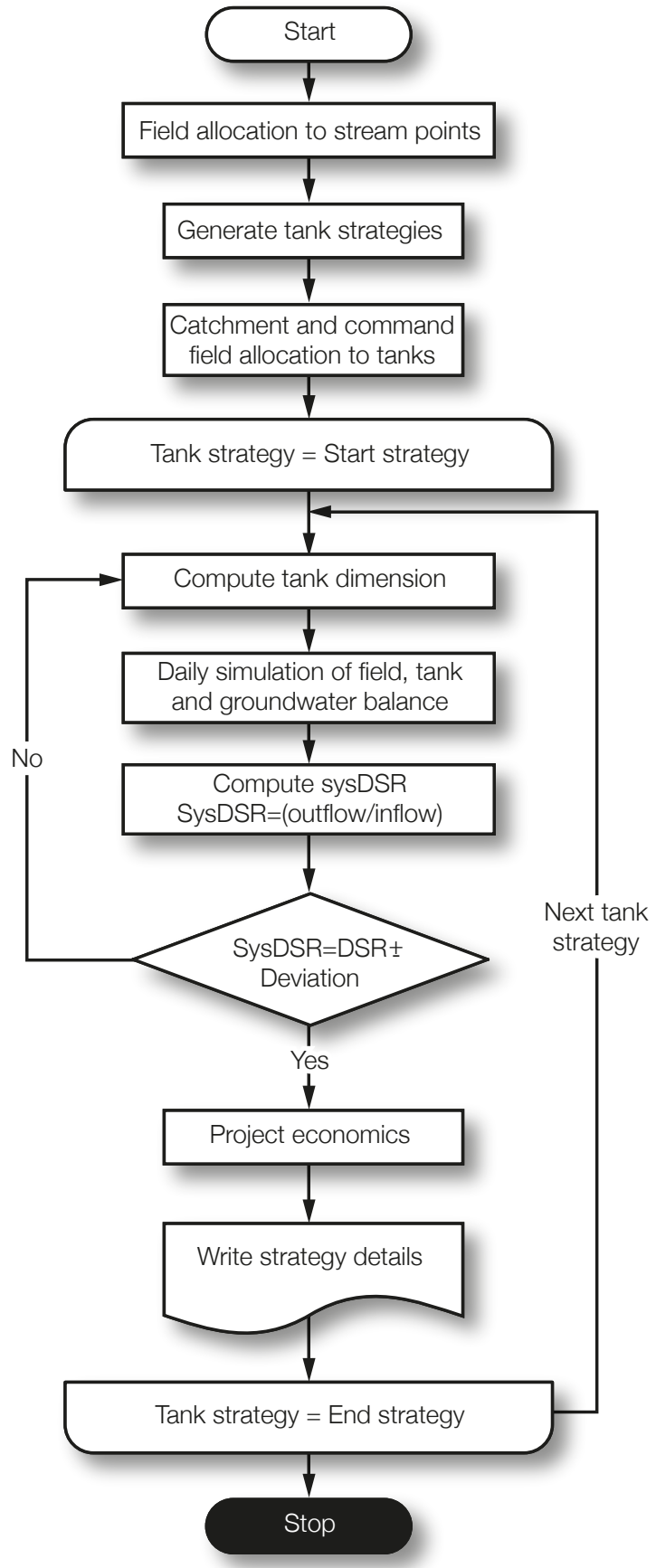




\section{Rainfall}

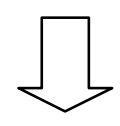

Actual evapotranspiration

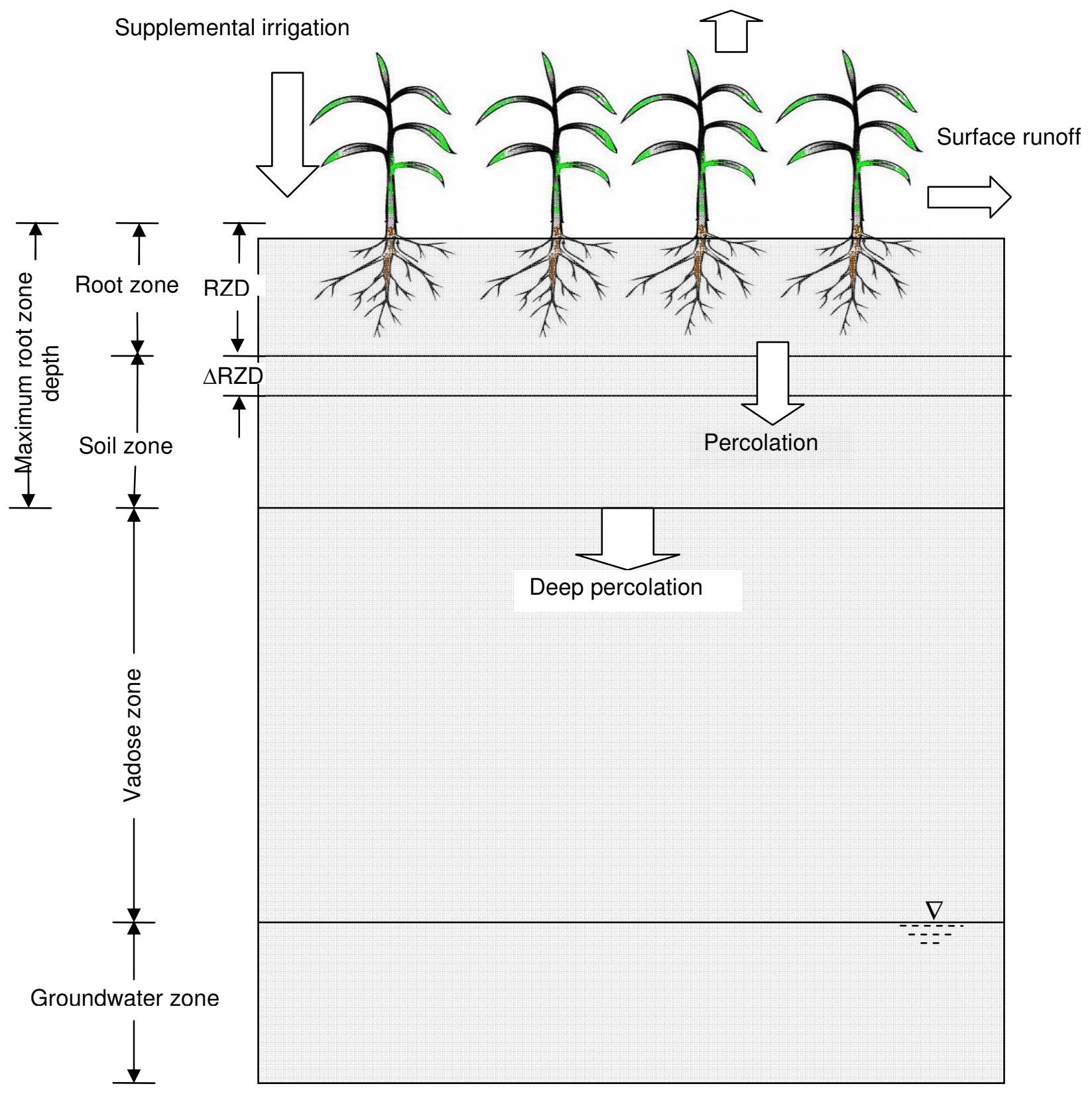

